\title{
Cryometry and excess thermodynamic functions in water soluble of the fullerenol $\mathrm{C}_{60}(\mathrm{OH})_{24}$
}

\author{
N. A. Charykov ${ }^{1,5}$, K. N. Semenov ${ }^{1,2,6}$, V. A. Keskinov ${ }^{1}$, N. A. Kulenova ${ }^{3}$, Z. K. Shaimardanov ${ }^{3}$, \\ B. K. Shaimardanova ${ }^{3}$, L. V. Gerasimova ${ }^{1}$, Ayat $\operatorname{Kanbar}^{1}$, D. G. Letenko ${ }^{4}$ \\ ${ }^{1}$ St. Petersburg State Technological Institute (Technical University), \\ Moskovsky prospect, 26 Saint-Petersburg, 190013, Russia \\ ${ }^{2}$ St. Petersburg State University,7/9 Universitetskaya emb., Saint-Petersburg, 199034, Russia \\ ${ }^{3}$ D. Serikbayev East Kazakhstan state technical university, \\ A. K. Protozanov Street, 69, Ust-Kamenogorsk city, 070004,The Republic of Kazakhstan \\ ${ }^{4}$ St. Petersburg State University of Architecture and Civil Engineering (SPSUACE), \\ 2-nd Krasnoarmeiskaya St. 4, 190005 St. Petersburg, Russia
}

${ }^{5}$ St. Petersburg Electrotechnical University “LETI”, ul. Professora Popova 5, 197376 St. Petersburg, Russia

${ }^{6}$ Pavlov First Saint Petersburg State Medical University

L'va Tolstogo str. 6-8 Saint Petersburg, 197022, Russia

keskinov@mail.ru

PACS 61.48.+c

DOI 10.17586/2220-8054-2020-11-2-205-213

\begin{abstract}
The temperature of water-ice crystallization initiation decreases $(\Delta \mathrm{T})$ were determined in the binary water solutions of water soluble fullerenol: $\mathrm{C}_{60}(\mathrm{OH})_{24}-\mathrm{H}_{2} \mathrm{O}$ at $272.85-273.15 \mathrm{~K}$. Solution concentrations (in molar fractions) vary over a wide range $x_{n a n o-c l u s t e r}=5.0 \cdot 10^{-6} \div$ $1.6 \cdot 10^{-4}$ a.un. Liquidus temperatures were determined with the help of Beckman thermometer with a linear resolution of the device scale $\frac{\Delta \mathrm{T}}{\Delta \mathrm{h}} \approx 0.01 \mathrm{~K} / \mathrm{mm}(\mathrm{h}$ - height of $\mathrm{Hg}$ capillary raising). For the thermodynamic description of the discussed systems, we have elaborated an original semi-empirical model, the virial decomposition asymmetric model (VD-AS), with assistance from partial molar functions of nano-clusters (activities and activity coefficients) were calculated. The Gibbs energies for the solutions and miscibility gap concentration regions were calculated. VD-AS model excellently describes pre-delamination or micro-heterogeneous-structure formation in the considered solutions. These calculations are confirmed by the dynamic light scattering data.
\end{abstract}

Keywords: fullerenol $\mathrm{C}_{60}(\mathrm{OH})_{24}$, water solutions, cryometry, excess functions, delamination.

Received: 19 February 2020

Revised: 1 March 2020

\section{Introduction}

The article is the development of the investigations, devoted to the synthesis, identification and investigation of physico-chemical properties of water soluble derivatives of light fullerene $\mathrm{C}_{60}$ and $\mathrm{C}_{70}$, such as: complexes of eithertwo-based dicarboxylic acids (malonates, oxalates), poly-hydroxylated forms (fullerenols), amino-acid derivatives (arginine, alanine) some other derivatives [1-32]. In these works, in particular, such physical-chemical properties of water solutions of light fullerene derivatives, depending on the solutions concentration, were investigated: polythermal solubility and crystal hydrate compositions; volume properties (density, average and partial components molar volumes); refraction indices, specific and molar refractions; conductivity and hydrogen indicator (seeming dissociation degrees and concentration dissociation constants); associates dimensions and electro-kinetic $\zeta$-potentials, some others.

The investigation of the excess thermodynamic functions in such systems (activities, activity coefficients, excess (or mixing) Gibbs energies (enthalpies, entropies) etc, as authors know, until this time was not provided, except for some original works [33-38]. In these articles, in the binary systems with the help of cryometry investigations, the authors determined the decrease of the temperatures of the beginning of ice crystallization (liquidus temperatures), water activities, water activity coefficients, and then, numerically solving the Gibbs-Duhem equation - activities and activity coefficients of fullerene derivatives. No other data, concerning excess function in considered systems, obtained, for example by isopiestic method, were not found, unfortunately. Meanwhile, such data may be very scientifically interesting, because these water solutions have very specific and rare consistent hierarchical type of association (vide infra). 


\section{Cryometry data in the binary water solutions of water soluble derivatives of light fullerenes}

The temperature of water-ice crystallization initiation decreases $(\Delta \mathrm{T})$ were determined in the binary water solutions of water soluble derivative of light fullerenes: $\mathrm{C}_{60}(\mathrm{OH})_{24}-\mathrm{H}_{2}$ at $272.85-273.15 \mathrm{~K}$. Solution concentrations (in molar fractions) vary in the wide range $\mathrm{X}_{\text {nano-cluster }}=5.0 \cdot 10^{-6} \div 1.6 \cdot 10^{-4}$ rel.un. Liquidus temperatures were determined with the help of Beckman thermometer with the linear resolution of the device scale $\frac{\Delta T}{\Delta \mathrm{h}} \approx 0.01 \mathrm{~K} / \mathrm{mm}$ ( $\mathrm{h}-$ height of $\mathrm{Hg}$ capillary raising). Cryometry data $\Delta \mathrm{T}\left(\mathrm{x}_{\text {nano-cluster }}\right)$ are depicted in the Fig. 1 and in Table 1.

TABLE 1. Cryometry data and excess thermodynamic functions in the binary system bis-adduct of light fullerene $\mathrm{C}_{70}$ and amino-acid - lysine $\mathrm{V}$ at $272.99-273.15 \mathrm{~K}$

\begin{tabular}{|c|c|c|c|c|}
\hline $\begin{array}{l}\text { Molar fraction of } \\
\mathrm{C}_{60}(\mathrm{OH})_{24} \text { in the } \\
\text { solution } \\
\mathrm{X}_{C_{60}(O H)_{24}} \\
\text { (rel.un.) }\end{array}$ & $\begin{array}{l}\text { Temperature of } \\
\text { the beginning of } \\
\text { ice crystal- } \\
\text { lization decrease } \\
\qquad \Delta \mathrm{T}(\mathrm{K})\end{array}$ & $\begin{array}{l}\ln \mathrm{a}_{H 2 O} \\
\ln \text { (water } \\
\text { activity) } \\
\text { (rel.un.) }\end{array}$ & $\begin{array}{c}\ln \gamma_{H 2 O} \\
\ln (\text { water activity } \\
\text { coefficient) } \\
\text { (rel.un.) }\end{array}$ & $\begin{array}{c}\ln \gamma_{C_{60}(O H) 24}^{a s} \\
\ln (\text { activity } \\
\text { coefficient of } \\
\mathrm{C}_{60}(\mathrm{OH})_{24} \\
\text { (rel.un.) }\end{array}$ \\
\hline 0.000 & 0.000 & 0.000 & 0.000 & 0.000 \\
\hline $1.083 \cdot 10^{-6}$ & 0.005 & $-5.86 \cdot 10^{-5}$ & $-5.75 \cdot 10^{-5}$ & 3.38 \\
\hline $2.166 \cdot 10^{-6}$ & 0.013 & $-1.44 \cdot 10^{-4}$ & $-1.42 \cdot 10^{-4}$ & 6.65 \\
\hline $4.332 \cdot 10^{-6}$ & 0.020 & $-2.22 \cdot 10^{-4}$ & $-2.18 \cdot 10^{-4}$ & 12.9 \\
\hline $8.66 \cdot 10^{-6}$ & 0.030 & $-3.33 \cdot 10^{-4}$ & $-3.25 \cdot 10^{-4}$ & 24.3 \\
\hline $1.73 \cdot 10^{-5}$ & 0.050 & $-5.49 \cdot 10^{-4}$ & $-5.32 \cdot 10^{-4}$ & 42.2 \\
\hline $3.46 \cdot 10^{-5}$ & 0.075 & $-8.22 \cdot 10^{-4}$ & $-7.87 \cdot 10^{-4}$ & 66.0 \\
\hline $6.92 \cdot 10^{-5}$ & 0.11 & -0.00122 & -0.00116 & 72.5 \\
\hline $1.38 \cdot 10^{-4}$ & 0.16 & -0.00178 & -0.00164 & 73.1 \\
\hline
\end{tabular}

One can see, that all dependencies $\Delta \mathrm{T}\left(\mathrm{x}_{\text {nano-cluster }}\right)$ are sharply nonlinear, which prove very high positive deviations of the solutions from ideality for all solutions, even when very diluted. In the Fig. 1 for the comparison by the arrow is represented the value $\Delta \mathrm{T}^{\text {id }}$ for the ideal non-electrolyte solution. We can see the experimental $\Delta \mathrm{T}$ exceeds $\Delta \mathrm{T}^{i d}$ one-two orders (for comparable concentrated and diluted solutions, correspondingly). So, one should expect probably gigantic positive deviations of the solution from the ideality in thermodynamic sense.

\section{Calculation of water excess functions}

For the calculation of water activity we have used well-known equation, got from the equality of the chemical $\mathrm{H}_{2} \mathrm{O}$ potentials in pure solid ice and non-ideal liquid solution [34-38]:

$$
\frac{-\Delta H_{W}^{f} \Delta T-\Delta C_{P} \Delta T^{2}}{R\left(T_{0}^{f}-\Delta T\right) T_{0}^{f}}=\ln a_{H 2 O},
$$

where $\Delta \mathrm{H}_{W}^{f}=5990 \mathrm{~J} / \mathrm{mole}, \Delta \mathrm{C}_{P}=-38.893 \mathrm{~J} /$ mole $\cdot \mathrm{K}, \mathrm{T}_{0}^{f}=273.15 \mathrm{~K}$ heat, temperature of ice fusion and change of heat capacity in the process of ice fusion, correspondingly. Equation (1) was displayed in the symmetrical normalization scale for thermodynamic functions for both solution components:

$$
\begin{gathered}
a_{H 2 O}\left(x_{H 2 O}=1\right)=\gamma_{H 2 O}\left(x_{H 2 O}=1\right)=1, \\
a_{\text {nano-cluster }}\left(x_{\text {nano-cluster }}=1\right)=\gamma_{\text {nano-cluster }}\left(x_{\text {nano-cluster }}=1\right)=1,
\end{gathered}
$$

where $x_{i}$ and $a_{i}, \gamma_{i}$ - molar fraction, activity and activity coefficient of i-th component.

Calculated data $\ln \left[\mathrm{a}_{H 2 O}\left(\mathrm{x}_{\text {nano-cluster }}\right)\right]$ are represented in Fig. 2 and Table 1. 


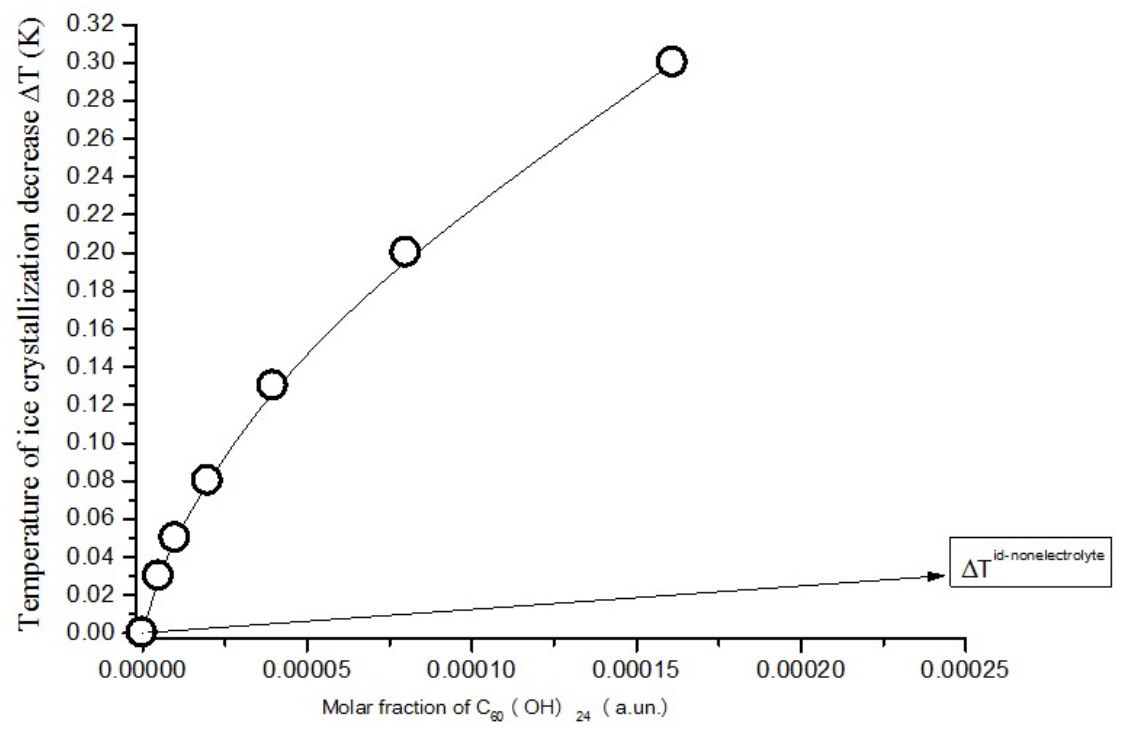

FIG. 1. Temperature of water-ice crystallization beginning (liquidus temperature) decrease $(\Delta \mathrm{T})$ against molar fraction concentration in the binary solutions: $\mathrm{C}_{60}(\mathrm{OH})_{24}-\mathrm{H}_{2} \mathrm{O}$ at $272.85-273.15 \mathrm{~K}$. Arrow shows $\Delta \mathrm{T}$-function for the ideal non-electrolyte solution

Further authors [33-38] calculated concentration dependencies $\ln \gamma_{H 2 O}$, derivatives $\frac{d \ln \gamma_{H 2 O}}{d x_{n a n o-c l u s t e r}}$ (numerically). Then, authors [33-38] (especially [36]) calculated the dependencies $\frac{d \ln \gamma_{\text {nano-cluster }}}{d x_{\text {nano-cluster }}}$, (according to classical differential Gibbs-Duhem differential equation) also numerically and at the end by numerical integration the dependencies $\ln \gamma_{\text {nano-cluster }}\left(\mathbf{x}_{\text {nano-cluster }}\right)$ were calculated. As a result, as was expected earlier, significant positive deviations of the solution from the ideality for the functions $\ln \gamma_{\text {nano-cluster }}$ were obtained $\ln \gamma_{\text {nano-cluster }} \approx$ $\mathrm{n}\left(10^{0} \div 10^{1}\right)$ (see Table 1 and lower - Fig. 4). Naturally, in all likelihood, no currently existing thermodynamic model can describe such non-trivial behavior of nano-cluster thermodynamic functions.

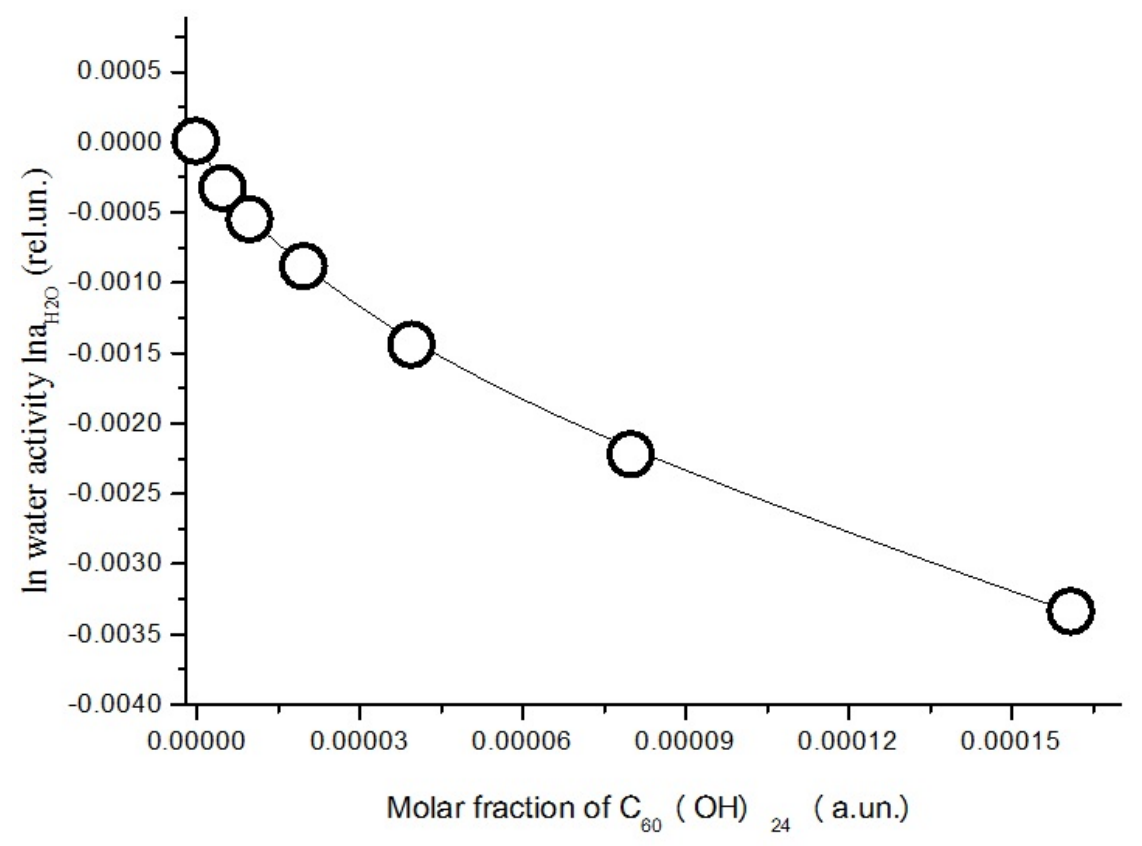

FIG. 2. Logarithm of water activity $\left(\operatorname{lna}_{\mathrm{H} 2 \mathrm{O}}\right)$ against molar fraction concentration in the binary solutions: $\mathrm{C}_{60}(\mathrm{OH})_{24}-\mathrm{H}_{2} \mathrm{O}$ at $272.85-273.15 \mathrm{~K}$ 


\section{Virial Decomposition Asymmetric Model - VD-AS}

For the description of such nontrivial thermodynamic behavior of considered water solutions, we have elaborated semi-empirical model VD-AS (Virial Decomposition Asymmetric Model), based on the virial decomposition of excess molar Gibbs energy on the solution for the components molar fractions. This technique has often been used for the thermodynamic description of binary and multicomponent systems with the different physical-chemical nature, such as: electrolyte solutions [39-42], non-electrolyte (semiconductor) melts [43-46], isovalent substitution solid solutions [47-49]. If one takes only one term in the decomposition for the binary system (corresponding to the invariant second virial coefficient), - see later equation (4) well-known strictly regular solutions model - RSM, is realized. Under the assumption of the temperature dependence for the only virial coefficient, the quasi-regular solution model - QRSM is realized. If one uses third virial coefficients for the decomposition, the sub-regular solution model SRSM, is realized. Finally, when one additionally takes into account the contribution of the electrostatic non-specific interactions (according to Debye-Huckel theory) Pitzer's model in different variants is realized.

So, let the following numeration: 1 - is the number of the dissolved component (nano-cluster in our case), $2-$ is the number of the solvent $\left(\mathrm{H}_{2} \mathrm{O}\right)$. Let us postulate the following expression:

$$
\frac{G^{e x}}{R T}=\left(n_{1}+n_{2}\right) \sum_{i=1} \sum_{j=1} X_{1}^{i} X_{2}^{j} * \lambda_{i j}=\frac{\sum_{i=1} \sum_{j=1} n_{1}^{i} n_{2}^{j} * \lambda_{i j}}{\left(n_{1}+n_{2}\right)^{i+j-1}},
$$

where $G^{e x}$ - full molar excess solution Gibbs energy, $R=8.31 \mathrm{~J} / \mathrm{K}, T$ - temperature $(\mathrm{K}), n_{i}$ and $X_{i}$ - molar number and molar fraction of $i$-th component, correspondingly, $\lambda_{i j}-i j$-th virial coefficient in the decomposition of $G^{e x} / R T$ on the component molar numbers. In other words, $\lambda_{i j}$ are naturally identified as divided by $R T$ specific energy of interaction of $i$ particles of the 1-st component and $j$ particles of the 2 -nd component. If one takes into account huge (two orders of magnitude) differences in components molar masses (1-st are heavy) and it's linear dimensions (almost one order - nanoclusters in our case are hollow), it is quite clear, that if upper limit of the summation according to the 1-st component is small natural number (not more than 4-6), that if upper limit of the summation according to the 2-st component may be more on one-two order.

Let us calculate excess thermodynamic functions of the components $\ln \gamma_{i}$ :

$$
\begin{aligned}
& \ln \gamma_{1}=\frac{\partial\left(G^{e x} / R T\right)}{\partial n_{1}}=\sum_{i=1} \sum_{j=1}\left[i-(i+j-1) X_{1}\right] X_{1}^{i-1} X_{2}^{j} * \lambda_{i j}, \\
& \ln \gamma_{2}=\frac{\partial\left(G^{e x} / R T\right)}{\partial n_{2}}=\sum_{i=1} \sum_{j=1}\left[j-(i+j-1) X_{2}\right] X_{1}^{i} X_{2}^{j-1} * \lambda_{i j} .
\end{aligned}
$$

In our case molar fractions $f$ the components are incomparable:

$$
X_{2}>>X_{1}, X_{2}>0.999 \approx 1 X_{1}<<1 .
$$

So, equations (5), (6) may be simplified:

$$
\ln \gamma_{2} \approx \sum_{i=1}(1-i) X_{1}^{i} \sum_{j=1} \lambda_{i j}=\sum_{i=2}(1-i) X_{1}^{i} \sum_{j=1} \lambda_{i j}
$$

From the systems (5), (6), (8) one can see that, they are agreed in thermodynamic sense, i.e. Gibbs-Duhem equation is valid at $\mathrm{T}, \mathrm{P}=\mathrm{const}$ :

$$
X_{1} d \ln \gamma_{1}+X_{2} d \ln \gamma_{2}=0
$$

or, for example from the equations (7) and (8), we can get identity:

$$
X_{1} \sum_{i=1} i(i-1) X_{1}^{i-2} \lambda_{i j} d X_{1}+\sum_{i=1}(1-i) i X_{1}^{i-1} \lambda_{i j} d X_{1}=0 .
$$

Let us transfer system (7), (8), denoting as $\Lambda_{i}$ summary virial coefficients:

$$
\sum_{j=1} \lambda_{i j}=\Lambda_{i}(T)
$$

So, in our conditions of consideration:

$$
\begin{gathered}
\ln \gamma_{1} \approx \sum_{i=1} i \Lambda_{i} X_{1}^{i-1} \\
\ln \gamma_{2} \approx \sum_{i=1}(1-i) \Lambda_{i} X_{1}^{i}=\sum_{i=2}(1-i) \Lambda_{i} X_{1}^{i}
\end{gathered}
$$


One can see, that, if $\Lambda_{1} \neq 0$, then logarithms of the limit activity coefficients $-\ln \gamma_{i}^{0}=\lim _{X 1 \rightarrow 0} \ln \gamma_{i}$, correspond to symmetrical method or normalization of the excess thermodynamic functions, namely:

$$
\begin{gathered}
\ln \gamma_{1}^{0}=\Lambda_{1} \neq 0, \quad \gamma_{1}\left(X_{1} \rightarrow 0\right)=\gamma_{1}^{0} \neq 1, \\
\ln \gamma_{2}^{0}=0, \quad \gamma_{2}\left(X_{1} \rightarrow 0\right)=1 .
\end{gathered}
$$

In our case incomparable more conveniently is to use asymmetrical normalization scale, (for this one should only demand the performing of the single condition $\left.\Lambda_{1}=0\right)$ :

$$
\begin{gathered}
\ln \gamma_{1}^{0}=0, \quad \gamma_{1}\left(X_{1} \rightarrow 0\right)=\gamma_{1}^{0}=1 \\
\ln \gamma_{2}^{0}=0, \quad \gamma_{2}\left(X_{1} \rightarrow 0\right)=1 \\
\ln \gamma_{1}^{a s s} \approx \sum_{i=2} i \Lambda_{i} X_{1}^{i-1} \\
\ln \gamma_{2}^{\text {ass }} \approx \sum_{i=2}(1-i) \Lambda_{i} X_{1}^{i}
\end{gathered}
$$

This normalization scale will be used by us always default.

Let us introduce the function $\frac{G^{m i x}}{R T}$ (divided by $R T$ molar Gibbs energy of mixing), the second isothermal isobaric concentration derivative of which is equal to the full solution molar Gibbs energy:

$$
\begin{gathered}
\frac{G^{m i x}}{R T}=X_{1} \ln X_{1}+X_{2} \ln X_{2}+X_{1} \ln \gamma_{1}+X_{2} \ln \gamma_{2}, \\
\frac{\partial\left[G^{m i x} / R T\right]}{\partial X_{1}}=\frac{1}{X_{1}}+\frac{1}{X_{2}}-\left(\ln X_{2}+1\right)+\sum_{i=1} i^{2} \Lambda_{i} X_{1}^{i-1}+\sum_{i=2}(1-i) \Lambda_{i}\left[i(i-1) X_{1}^{i-2}-(i+1) X_{1}^{i-1}\right] \\
\frac{\partial^{2}\left[G^{\text {mix }- \text { ass }} / R T\right]}{\partial X_{1}^{2}} \approx \frac{1}{X_{1}}+\sum_{i=2} i(i-1) \Lambda_{i} X_{1}^{i-2} .
\end{gathered}
$$

Absolutely similarly we can calculate (divided by $R T$ ) first isothermal - isobaric concentration derivative of the chemical potential or logarithm of the activity of the 1-st component - $\mu_{1}$ and $\ln a_{1}$, correspondingly:

$$
\frac{1}{R T} \frac{\partial \mu_{1}}{\partial X_{1}}=\frac{\partial \ln a_{1}}{\partial X_{1}} \approx \frac{1}{X_{1}}+\sum_{i=2} i(i-1) \Lambda_{i} X_{1}^{i-2}
$$

So, the equation of the diffusional (spinodal) stability loss will be the following:

$$
G_{11}^{m i x-a s s}=\frac{\partial^{2}\left[G^{m i x-a s s} / R T\right]}{\partial X_{1}^{2}}=\frac{\partial \ln a_{1}}{\partial X_{1}} \approx \frac{1}{X_{1}}+\sum_{i=2} i(i-1) \Lambda_{i} X_{1}^{i-2}=0 .
$$

\section{Application of VD-AS model to the description water soluble derivatives of light fullerenes water solutions. Calculation of nanoclusters excess functions. Miscibility gaps}

Preliminary calculation shows that the 3-term approximation in VD-AS - model (i.e. $i=2,3,4$ ) is sufficient for more or less successful for the excess thermodynamic functions calculation with the satisfactory accuracy:

$$
\begin{aligned}
& \ln \gamma_{1}^{a s s} \approx 2 \Lambda_{2} X_{1}+3 \Lambda_{3} X_{1}^{2}+4 \Lambda_{4} X_{1}^{3}, \\
& \ln \gamma_{2}^{a s s} \approx-\Lambda_{2} X_{1}^{2}-2 \Lambda_{3} X_{1}^{3}-3 \Lambda_{4} X_{1}^{4} .
\end{aligned}
$$

So, the equation of the diffusional (spinodal) stability loss will be the following:

$$
12 \Lambda_{4} X_{1}^{3}+6 \Lambda_{3} X_{1}^{2}+2 \Lambda_{2} X_{1}+1=0,
$$

or is elementary explicitly solved relatively $\mathrm{X}_{1}$ (according to Cardano formula) cubic equation.

All calculated parameters of VD-AS - model is represented in Table 2.

In all considered binary systems we calculated concentration dependencies $\ln \gamma_{H 2 O}$ (see Table 1):

$$
\ln \gamma_{2}=\ln _{H 2 O}=\ln a_{H 2 O}-\ln X_{H 2 O}=\ln a_{H 2 O}-\ln \left(1-X_{1}\right),
$$

and from these functions $\ln \gamma_{2}\left(\mathrm{X}_{1}\right)$ according to equation (26) we determined parameters of VD-AS model: $\left(\Lambda_{2}, \Lambda_{3}\right.$, $\Lambda_{4}$ ) (see Table 2).

Formally, the huge values of summary virial coefficients $\Lambda_{i}$, in general, are not surprising, if we remember that, according to the physical sense, the last ones are the sums of the rows, consist of probably thousands terms, responsible for the energies of interactions of few nano-clusters with very large number of water molecules. 
TABLE 2. Parameters of model VD-AS $\left(\Lambda_{2}, \Lambda_{3}, \Lambda_{4}\right)$ and concentration boards of diffusion instability regions $\left(\mathrm{X}^{\text {diff-instab }}\right)$ in the binary system: $\mathrm{C}_{60}(\mathrm{OH})_{24}-\mathrm{H}_{2} \mathrm{O} 272.85-273.15 \mathrm{~K}$

\begin{tabular}{|c|c|c|c|}
\hline \multicolumn{4}{|c|}{ VD-AS model parameters (rel.un.) } \\
\hline$\Lambda_{2}$ (aun.) & $\Lambda_{3}$ (aun.) & $\Lambda_{4}$ (aun.) & $\approx \mathrm{X}^{\text {diff-instab }}$ (a.un.) \\
\hline $2.10 \cdot 10^{6}$ & $-1.58 \cdot 10^{10}$ & $3.99 \cdot 10^{13}$ & $6.0 \cdot 10^{-5}$ \\
\hline
\end{tabular}

Then, according to the equation (24) we calculated concentration dependencies $\ln \gamma_{1}^{\text {ass }}\left(X_{1}\right)$ (See Table 1 and Fig. 3). From Fig. 3 one can see that some dependencies $\ln \gamma_{1}^{a s s}\left(X_{1}\right)$ will cross through the maximum at the values: $X_{1} \approx 1.5 \cdot 10^{-4}$ rel.un. (in our case, it lays slightly beyond the investigated concentration range). Maximum state may be determined easily, form the equation (24), solving square equation:

$$
\frac{1}{2} \frac{d \ln \gamma_{1}^{a s s}}{d X_{1}}=\Lambda_{2}+3 \Lambda_{3} X_{1}^{+} 6 \Lambda_{4} X_{1}^{2}=0
$$

In our opinion, it interesting to compare cryometry data in these system $\mathrm{C}_{60}(\mathrm{OH})_{24}-\mathrm{H}_{2} \mathrm{O}$ (pure derivative without any traces on Na-substituted fulerenol forms, such as $\mathrm{C}_{60}(\mathrm{OH})_{23} \mathrm{ONa}$ ) and in the system fullerenol-d $-\mathrm{H}_{2} \mathrm{O}$ (mix of $\mathrm{C}_{60}(\mathrm{OH})_{22}, \mathrm{C}_{60}(\mathrm{OH})_{23}, \mathrm{C}_{60}(\mathrm{OH})_{24}$ etc with the traces of sodium mono-substituted forms - nearly $10^{-3}$ mol. \%). If Fig. 3 one can observe very good agreement between our data and data from [36], despite on some inconsistency in the composition.

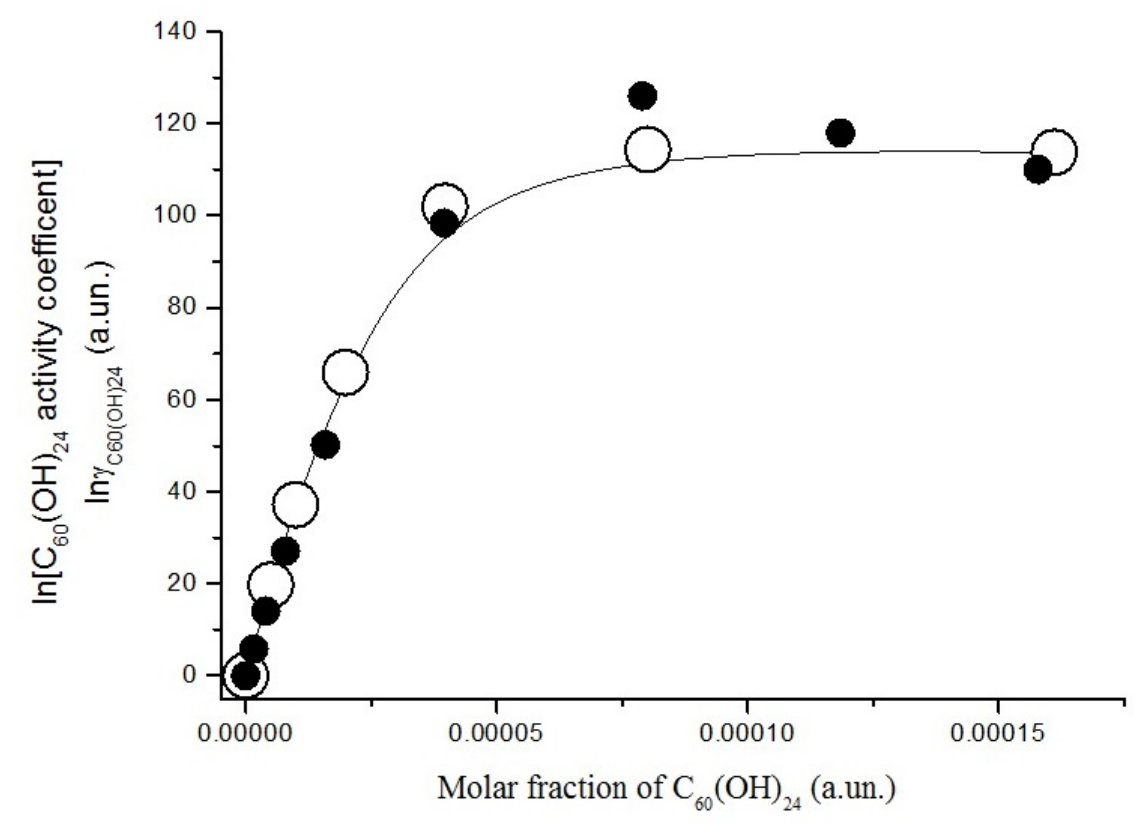

FIG. 3. Logarithm of light fullerene water soluble derivative activity $\mathrm{C}_{60}(\mathrm{OH})_{24}-\mathrm{H}_{2} \mathrm{O}$ at 272.85$273.15 \mathrm{~K}$ (open points - our calculation; solid points symbolize experimental cryometry data from [36] in the related system fullerenol-d $-\mathrm{H}_{2} \mathrm{O}$ )

Then, according to the equation (27), we determined the boards of diffusional stability loss - $X^{\text {diff }}$ (see Table 2 and Fig. 4), solving cube equation:

$$
F=12 \Lambda_{4} X_{1}^{3}+6 \Lambda_{3} X_{1}^{2}+{ }^{2} \Lambda_{2} X_{1}+1=0 .
$$

As one can see from Table 2, all cubic equations (27) for our considered systems have real positive roots in real concentration ranges, which correspond to the existence of liquid solutions of nano-clusters in water. From this fact, one can conclude, in some concentration range: $\mathrm{X}_{1}^{\text {diff }} \approx 6.0 \cdot 10^{-5}$ rel.un. system begins to flake or may be preflake (see later). In the Fig. 4 the concentration dependencies of the diffusional instability functions $F^{d i f f-i n s t a b}=$ $12 \Lambda_{4} X_{1}^{3}+6 \Lambda_{3} X_{1}^{2}+{ }^{2} \Lambda_{2} X_{1}+1=0$ is represented. From Fig. 4, we see that almost all functions $\mathrm{F}^{d i f f-i n s t a b}\left(\mathrm{X}_{1}\right)$ have the initial intersection with the abscissa axis (red point), which corresponds to the diffusional stability loss. 


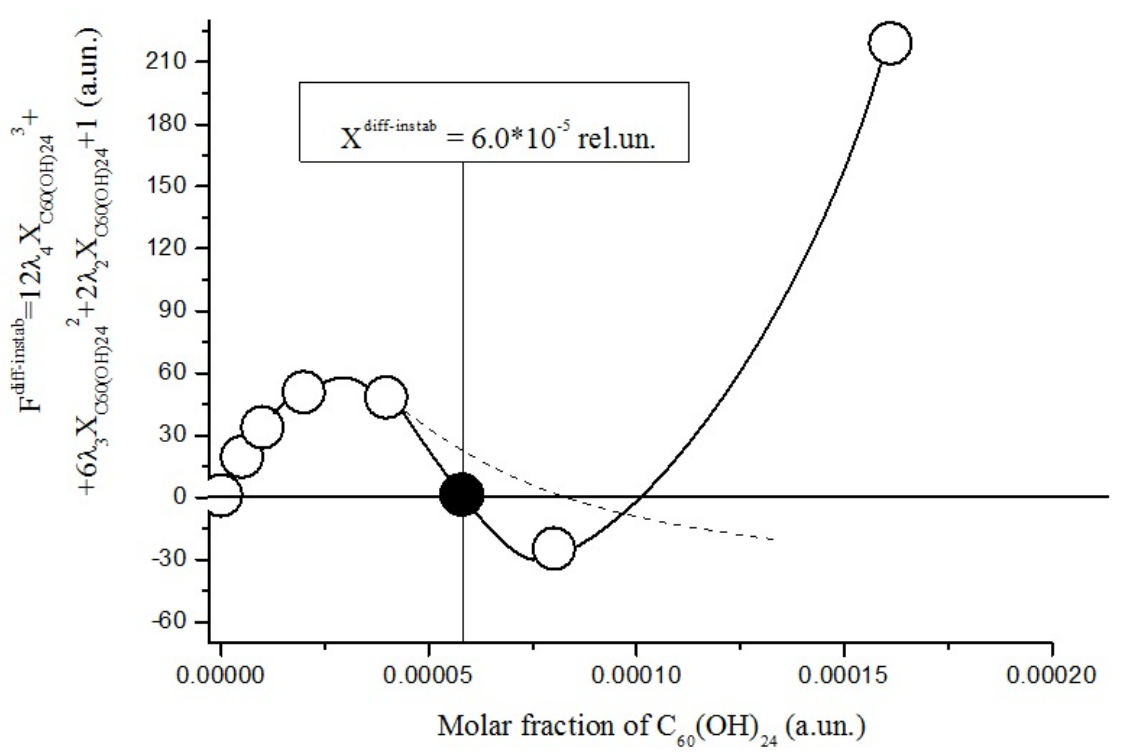

FIG. 4. Instability board function $\mathrm{F}$ against molar fraction concentration in the binary solutions: $\mathrm{C}_{60}(\mathrm{OH})_{24}-\mathrm{H}_{2} \mathrm{O}$ at $272.85-273.15 \mathrm{~K}$ (solid point corresponds to the border of solutions instability region, dash curve corresponds to the border of solutions instability region from [36]) solutions.

As expected, even such minor amounts of Na-substituted forms considerably stabilized phase instable nano-cluster

\section{Conclusions}

Thus, the water soluble fullerenol $\mathrm{C}_{60}(\mathrm{OH})_{24}$ demonstrated very high positive deviations from the ideality, which in turn caused formation of micro-heterogeneous system or pre-delamination in the liquid phase. VD-AS semiempirical thermodynamic model provided a sufficiently accurate description of the concentration dependence of excess thermodynamic functions in this system.

\section{Acknowledgements}

This work was supported by Russian Foundation for Basic Research (RFBR) (Projects Nos. 18-08-00143 A, 19-015-00469 A, and 19-016-00003 A).

\section{References}

[1] Li J., Takeuchi A., Ozawa M. et al. $\mathrm{C}_{60}$ fullerol formation catalysed by quaternary ammonium hydroxides. J. Chem.Soc.Chem. Commun., 1993, 23, P. 1784.

[2] Chiang L.Y., Bhonsle J.B., Wang L. et al. Efficient one-ask synthesis of water-soluble fullerenes. Tetrahedron, 1996,52 , P. 4963.

[3] Chiang L.Y., Upasani R.B., Swirczewski J.W. Versatile nitronium chemistry for C 60 fullerene functionalization. J.Am.Chem. Soc., 1992, 114, P. 10154.

[4] Meier M.S., Kiegiel J. Preparation and characterization of the fullerene diols 1,2- $\mathrm{C}_{60}(\mathrm{OH})_{2}, 1,2-\mathrm{C}_{70}(\mathrm{OH})_{2}$, and 5,6-C $70(\mathrm{OH})_{2}$. Org. Lett., 2001, 3, P. 1717.

[5] Szymanska L., Radecka H., Radecki J. et al. Electrochemical impedance spectroscopy for study of amyloid-peptide interactions with (-) nicotine ditartrate and (-) cotinine. Biosens. Bioelectron, 2001, 16, P. 911.

[6] Mirkov S.M., Djordjevic A.N., Andric N.L. et al. Modulating activity of fullerol $\mathrm{C}_{60}(\mathrm{OH})_{22}$ on doxorubicin-induced cyto-toxicity. Nitric Oxide, 2004, 11, P. 201.

[7] Kokubo K., Matsubayashi K., Tategaki H. et al. Facile synthesis of highly water-soluble fullerenes more than half-covered by hydroxyl groups. ACS Nano, 2008, 2(2), P. 327.

[8] Yang J.M., He W., Ping H. et al. The scavenging of reactive oxygen species and water soluble fullerene synthesis. Chinese. J. Chem., 2004, 22(9), P. 1008.

[9] Sheng W., Ping H., Jian Min Z. et al. Novel and efficient synthesis of water-soluble [C 60 ] fullerenol by solvent-free reaction. Synthetic Communications, 2005, 35(13), P. 1803.

[10] Chiang Long Y. Fullerene Derivatives as Free Radical Scavengers. US patent 5648523. July 15, 1997.

[11] Lamparth I., Hirsch A. Water-soluble malonic acid derivatives of $\mathrm{C}_{60}$ with a deffined three-dimensional structure J. Chem. Soc. Chem. Commun., 1994, P. 1727-1728.

[12] Liang Bing GAN, Chu Ping LUO. Water-soluble fullerene derivatives, synthesis and characterization of alanine $\mathrm{C}_{60}$ adducts. Chinese Chemical letters, 1994, 5(4), P. 275278. 
[13] Kotelnikova R.A., Kotelnikov A.I., Bogdanov G.N., Romanova V.S., Kuleshova E.F., Parnes Z.N., Vol'pin M.E. Membranotropic properties of the water soluble amino acid and peptide derivatives of fullerene $\mathrm{C}_{60}$. FEBS Lett., 1996, 389, P. 111-114.

[14] Hu Z., Guan W., Wang W., Huang L., Tang X., Xu H., Zhu Z., Xie X., Xing H. Synthesis of amphiphilic amino acid C 60 derivatives and their protective effect on hydrogen peroxide-induced apoptosis in rat pheochromocytoma cells. Carbon, 2008, 46, P. 99-109.

[15] Kumar A., Rao M.V., Menon S.K. Photoinduced DNA cleavage by fullerene-lysine conjugate. Tetrahedron Lett., 2009 , 50, P. $6526-6530$.

[16] Jiang G., Yin F., Duan J., Li G. Synthesis and properties of novel water-soluble fullerene glycine derivatives as new materials for cancer therapy. J. Mater. Sci: Mater. Med, 2015, 26, P. 1-7.

[17] Grigoriev V.V., Petrova L.N., Ivanova T.A., Kotel'nikova R.A., Bogdanov G.N., Poletayeva D.A., Faingold I.I., Mishchenko D.V., Romanova V.S., Kotel'nikov A.I., Bachurin S.O. Study of the neuroprotective action of hybrid structures based onfullerene C 60. Biology Bull, 2011, 38, P. 125-131.

[18] Kotel'nikova R.A., Faingol'd I.I., Poletaeva D.A., Mishchenko D.V., Romanova V.S., Shtol'ko V.N., Bogdanov G.N.,Rybkin A.Yu., Frog E.S., Smolina A.V., Kushch A.A., Fedorova N.E., Kotel'nikov A.I. Antioxidant properties of water-soluble amino acid derivatives of fullerenes and their role in the inhibition of herpes virus infection. Rus. Chem. Bull., 2011, 6, P. 1172-1176.

[19] Leon A., Jalbout A.F., Basiuk V.A. Fullerene-amino acid interactions. A theoretical study. Chem. Phys. Lett., 2008,452 , P. 306314.

[20] Hu Y.H., Ruckenstein E. Steam reforming products used as a hydrogen resource for hydrogen storage in Li 2 N. J. Mol. Struct. Theochem., 2008, 865, P. 94-97.

[21] Semenov K.N., Charykov N.A., Postnov V.N., Sharoyko V.V., Murin I.V. Phase equilibria in fullerene-containing systems as a basis for development of manufacture and application processes for nanocarbon materials. Rus. Chem. Rev., 2016, 85, P. 38-59.

[22] Semenov K.N., Charykov N.A., Murin I.V., Pukharenko Yu.V. Physico-Chemical Properties of C6060-tris-malonic-derivative Water Solutions. J. of Molecular Liquids, 2015, 202, P. 50-58.

[23] Semenov K.N., Charykov N.A., Murin I.V., Pukharenko Yu.V. Physico-chemical properties of the fullerenol-70 water solutions. J. of Molecular Liquids, 2015, 202, P. 1-8.

[24] Nikolay A. Charykov, Konstantin N. Semenov, Enriqueta R. Lypez, Josefa Fernndez ${ }^{c}$, Evgeny B. Serebryakov, Viktor A. Keskinov ${ }^{a}$, Igor V. Murin. Excess thermodynamic functions in aqueous systems containing soluble fullerene derivatives. J. of Molecule Liquids, 2018, 256, P. 305-311.

[25] Serebryakov E.B., Semenov K.N., Stepanyuk I.V., Charykov N.A., Mescheryakov A.N., Zhukov A.N., Alexey V. Chaplygin A.V., Murin I.V. Physico-chemical properties of the $\mathrm{C}_{70}$-L-lysine aqueous solutions. J. of Molecule Liquids, 2018, 256, P. 507-518.

[26] Yur'ev G.O., Lelet M.I., Pochkayeva E.A., Petrov A.V., Semenov K.N., Charykov N.A., Podolskiy N.E., Dulneva L.L., Sharoyko V.V., Murin I.V., Thermodynamic and thermal properties of the $\mathrm{C}_{60}$-L-Arg derivative. J. Chem. Thermodynamics, 2018, 127, P. 39-44.

[27] Podolsky N.E., Marcos M.A., Cabaleiro D., Semenov K.N., Luis Lugo, Petrov A.V., Charykov N.A., Sharoyko V.V., Vlasov T.D., Murin I.V. Physico-chemical properties of $\mathrm{C}_{6} \mathrm{O}(\mathrm{OH}) 22-24$ water solutions: density, viscosity, refraction index, isobaric heat capacity and antioxidant activity. J. of Mol. Liq, 2019, 278, P. 342-355.

[28] Podolsky N., Lelet M., Ageev S., Novikov A., Petrov A., Mazur A., Semenov K., Charykov N., Vasina L., Murin I. Thermodynamic properties from calorimetry and density functional theory and the thermogravimetric analysis of the fullerene derivative $\mathrm{C}_{60}(\mathrm{OH})_{40}$. Journal of Chemical \& Engineering Data, 2019, 64(4), P. 1480-1487.

[29] Serebryakov E.B., Zakusilo D.N., Semenov K.N., Charyov N.A., Akentiev A.V., Noskov B.A., Petrov A.V., Podolsky N.E., Mazur A.S., Dul'neva L.V., Murin I.V. Physico-chemical properties of $\mathrm{C}_{70}$-1-threonine bisadduct $\left(\mathrm{C}_{70}\left(\mathrm{C}_{4} \mathrm{H}_{9} \mathrm{NO}_{2}\right)_{2}\right)$ aqueous solutions. Journal of Molecular Liquids, 2019, 279, P. 687-699.

[30] Petrenko V.V., Charykov N.A., Semenov K.N., Keskinov V.A., Kurilenko A.V., Semenyuk V.A., Saf'annikov N.M. Synthesis, Identification and Physical-Chemical Properties of Bis-Adduct of $\mathrm{C}_{60}$ with Histidine. Nanotechnology Science and Technology. Applied Aspects of Nanophysics and Nano-engineering, 2019, P. 1-6.

[31] Semenyuk V.A., Semenov K.N., Charykov N.A., Keskinov V.A., Petrenko V.V., Kurilenko A.V., Saf'annikov N.M. Tris-Adduct of light Fullerene $\mathrm{C}_{70}$ with Indespensible Aminoacide Lysine. Nanotechnology Science and Technology. Applied Aspects Of Nanophysics and Nanoengineering, 2019, P. 7-12.

[32] Nikolaev D.N., Podolsky N.E., Lelet M.I., Iamalova N.R., Shemchuk O.S., Ageev S.V., Petrov A.V., Semenov K.N., Charykov N.A., Piotrovskiy L.B., Murin I.V. Thermodynamic and quantum chemical investigation of the monocarboxylated fullerene $\mathrm{C}_{60} \mathrm{CHCOOH} \mathrm{J}$. Chem. Thermodynamics, 2020, 140, P. 105898.

[33] Matuzenko M.Yu., Shestopalova A.A., Semenov K.N., Charykov N.A., Keskinov V.A. Cryometry and excess functions of the adduct of light fullerene $\mathrm{C}_{60}$ and arginine $\mathrm{C}_{60}\left(\mathrm{C}_{6} \mathrm{H}_{12} \mathrm{NAN}_{4} \mathrm{O}_{2}\right)_{8} \mathrm{H}_{8}$ aqueous solutions. Nanosystems: Physics, Chemistry, Mathematics, 2015, 6(5), P. 715-725.

[34] Matuzenko M.Yu., Tyurin D.P., Manyakina O.S., Semenov K.N., Charykov N.A., Ivanova K.V., Keskinov V.A. Cryometry and excess functions of fullerenols and trismalonates of light fullerenes $\mathrm{C}_{60}(\mathrm{OH})_{22-24}$ and $\mathrm{C}_{70}\left[=\mathrm{C}(\mathrm{COOH})_{2}\right]_{3}$, aqueous solutions. Nanosystems: Physics, Chemistry, Mathematics, 2015, 6(4), P. 704-714.

[35] Charykov N.A., Semenov K.N., Keskinov V.V., Garamova P.V., Tyurin D.P., Semenyuk I.V., Petrenko V.V., Kurilenko V.V., Matuzenko M.Yu., Kulenova N.A., Zolotarev A.A., Letenko D.G. Cryometry data in the binary systems bis-adduct of $\mathrm{C}_{60}$ and indispensable aminoacids - lysine, threonine, oxyproline. Nanosystems: Physics, Chemistry, Mathematics, 2017, 8(3), P. 397-405.

[36] Safyannikov N.M., Charykov N.A., Garamova P.V., Semenov K.N., Keskinov V.A., Kurilenko A.V., Cherepcova I.A., Tyurin D.P., Klepikov V.V., Matuzenko M.Yu., Kulenova N.A., Zolotarev A.A. Cryometry data in the binary systems bis-adduct of $\mathrm{C}_{60}$ and indispensable aminoacids - lysine, threonine, oxyproline. Nanosystems: Physics, Chemistry, Mathematics, 2018, 9(1), P. 46-49.

[37] Charykov N.A., Semenov K.N., Lypez E.R., Fernndez J., Serebryakov E.B., Keskinov V.A., Murin I.V. Excess thermodynamic functions in aqueous systems containing soluble fullerene derivatives. J. of Molecule Liquids, 2018, 256, P. 305-311.

[38] Semenov K.N., Kurilenko A.V., Charykov N.A., Keskinov V.A., Vorob'ev A.L., Shaimardanov Zh.K., Kulenova N.A., Onalbaeva Zh.S., and Letenko D.G. Solubility, Thermal analysis and association of bis-adducts of light fullerene $\mathrm{C}_{60}$ and amino-acids: lysine, threonine and oxyproline in water solutions. Russian Journal of Physical Chemistry A, 2019, 93(7), P. 1258-1265.

[39] Pitzer K.S., Pitzer K.S. J.Phys.Chem., 1973, 77(2), P. 268-277.

[40] Pitzer K.S., Kim J.J. Activity and osmotic coefficients for mixed electrolytes. J.Amer.Chem.Soc., 1974, 96(28), P. 5701-5707. 
[41] Filippov V.K., Charykov N.A., Rumyantsev A.V. The generalization of Pitzer's method on the system with complex formation in the solutions. Rep. Rus. Acad. Sciences. Seria: Physics-Chemistry, 1987, 296(3), P. 665-668.

[42] Carykova M.V., Charykov N.A. Thermodynamic modeling of evaporate sedimentation processes. SPb: Nauka, 2003,257 p.

[43] Charykov N.A., Litvak A.M., Mikhailova M.P., Moiseev K.D., Yakovlev Yu.P. Solid solution $\operatorname{In}_{x} \mathrm{Ga}_{1-x} \mathrm{As}_{\mathrm{SSb}} \mathrm{P}_{1-y-z}$. New material of IR opto-electronics. I. Thermodynamic analysis of production conditions for solid solutions, iso-periodic to the substrates InAs and GaSb, by liquid phase epitaxy method. Rus. Phys. and Tech. Semic., 1997, 31(4), P. 410-415.

[44] Litvak A.M., Charykov N.A. New thermodynamic method of calculation of melt-solid phase equilibria (for the example of A3B5 systems). Rus.J.Phys.Chem., 1990, 64(9), P. 2331-2335.

[45] Litvak A.M., Moiseev K.D., Charykov N.A., Yakovlev Yu.P. Hetero-structures InlxGa ${ }_{1-x} \mathrm{As}_{y} \mathrm{Sb}_{1-y} / \mathrm{InAs}$ production by LPE method. Rus. Tech. Phys. Lett., 1990, 16(13), P. 41-45.

[46] Baranov A.N., Guseinov A.A., Litvak A.M., Popov A.A., Charykov N.A., Sherstnev V.C., Yakovlev Yu.P. Production of solid solutions $\mathrm{InxGa}_{1-x} \mathrm{As}_{y} \mathrm{Sb}_{1-y}$, iso-periodic to GaSb, nearby miscibility gap. Rus. Tech. Phys. Lett., 1990, 16(5), P. $33-38$.

[47] Stringfellow G.B. Calculation of energy band gaps in quaternary III-IV alloys. J.Elecrctron. Mat., 1981, 10(5), P. 919-936.

[48] Stringfellow G.B. Calculation of ternary and quaternary III-V phase diagrams. J.Cryst.Growth, 1982, 58, P. 194-202.

[49] Litvak A.M., Charykov N.A. Melt-solid phase equilibria in the system Pb-InAs-InSb. Rus.J.Neorg.Chem., 1990, 35(12), P. 3059-3062. 